\title{
Use and analysis of UV varnish printed braille information on commercial packaging products
}

\begin{abstract}
This paper investigates the possibility of reproducing Braille by UV ink-jet printing on self-adhesive labels, previously printed by flexo printing technology. The aim was to determine whether it is possible to reproduce Braille, the degree of quality of created Braille dots (cells), the legibility of Braille text, and how many layers of varnish are necessary for quality reproduction. The Braille letter was applied to the previously printed label (design) using 8, 10, 12, 14 and 16 layers of varnish. It has been found that it is possible to reproduce a quality and legible Braille. With the increase in the number of layers, the assessment of legibility and quality of reproduction by the respondents also increased. Samples reproduced with 12 layers of varnish received a very good grade of legibility and good grade for quality of Braille. Samples reproduced with 8 and 10 layers received bad grades for legibility, and even worse for quality, while samples with a higher number of layers of varnish, 14 and 16, received even better grades. The threshold for quality reproduction would therefore be the use of 12 layers of varnish, where a good ratio of workmanship and economy is obtained.
\end{abstract}

\section{KEY WORDS}

Braille printing, UV ink-jet, UV varnish, blind, vision impairment

\author{
Slaven Miloš ${ }^{1}$ (1) \\ Đorđe Vujčić ${ }^{2}$ \\ Igor Majnarić ${ }^{1}$ (i) \\ ${ }^{1}$ University of Zagreb, \\ Faculty of Graphic Arts, Graphic \\ engineering, Zagreb, Croatia \\ ${ }^{2}$ University of Banja Luka, \\ Faculty of Technology, Graphic \\ engineering, Banja Luka, \\ Bosnia and Herzegovina
}

Corresponding author: Đorđe Vujčić e-mail:djordje.vujcic@tf.unibl.org

\section{Introduction}

Based on statistical data, it can be concluded that visual impairment is a significant health problem (Pascolini \& Mariotti, 2011; Hashemi et al., 2017; WHO, 2019). It is estimated that at least 2.2 billion people worldwide have some level of visual impairment, including blindness. According to statistics from 2015, 36 million people worldwide are blind (visual acuity worse than 3/60),
217 million have moderate or severe vision impairment (worse than 6/18, but equal to or better than 3/60) and 189 million have mild vision impairment (worse than 6/12, but equal to or better than $6 / 18)^{1}$. It is estimated that 1.8 billion people have near vision impairment (Bourne et al., 2017; Fricke et al., 2018; WHO, 2019). In percentage $3.44 \%$ of people have distance vision impairment (0.49\% are blind and $2.95 \%$ have moderate or severe vision impairment) (Ackland, Resnikoff \& Bourne, 2017).

\footnotetext{
${ }^{1}$ Visual acuity

Visual acuity is a simple, non-invasive measure of the ability of the visual system to distinguish two points of high contrast in space (WHO, 2019).

Distance visual acuity is usually assessed using a visuion chart at a certain distance (usually 6 meters (or 20 feet)). The smallest line read on the chart is written as a fraction, where the counter refers to the distance from which the chart is observed, and the denominator is the distance at which the "healthy" eye is able to read that line on the chart. For example, visual acuity $6 / 18$ means that at 6 meters from the visuion chart a person can read a letter that someone with normal vision could see at 18 meters. "Normal" vision is considered to be 6/6 (WHO, 2019).

Near visual acuity is measured according to the smallest print size that a person can notice at a given test distance. In a population survey, near-visual impairment is usually classified as a near visual acuity less than $\mathrm{N} 6$ or $\mathrm{m} 0.8$ at 40 centimeters, with $\mathrm{N}$ referring to the print size based on the point system used in the printing ondustry. industry, and 6 is the font size equivalent to the newspaper print (WHO, 2019).
} 
Estimates show that there are more than 30 million blind and partially sighted people in geographical Europe. On average, 1 in 30 Europeans faces vision loss. Trends in Europe also show that women are more susceptible to visual impairment than men and that vision loss is closely linked to aging (one in three citizens over the age of 65 faces vision loss; $90 \%$ of people with visual impairment are over the age of 65) (EBU, 2019).

It is very important to provide blind and partially sighted people with an environment in which they will feel safe and have access to the necessary information. This can, among other things, be achieved by labelling products in Braille (Havenko et al., 2013). According to the European Directive 2004/27/EC (European Commission, 2005), labelling of pharmaceutical products has been mandatory since 2005 , but it is expected that in the near future it will be mandatory to label a larger number of consumer products: food products, products for personal hygiene and care, products for space hygiene, etc. In some countries, Braille product labelling has already been extended to some other product categories, in addition to pharmaceutical products.

Braille is a universally accepted tactile reading and writing system for the blind and visually impaired (European Commission, 2005; Royal Blind, 2019). Frenchman Louise Braille, who went blind in the third year of his life, invented Braille in 1825, and it was named after him (European Commission, 2005; VisionAware, 2019). It can be said that Braille is a code that can be used to read and write in many languages (American Foundation for the Blind, 2019; European Commission, 2005; Royal Blind, 2019). It enables literacy and gives an individual the opportunity to become acquainted with spelling, punctuation, paragraph and other formatting rules (Royal Blind, 2019). It is a system that consists of raised dots, which are read tactilely, by crossing a finger over them (American Foundation for the Blind, 2019). One complete cell of Braille consists of six raised dots placed in two parallel vertical columns, three dots in each (it looks like the number 6 on the dice). Each dot is assigned a number from 1 to 6 . Thus, the upper left dot is assigned the number 1, dots below 2 and 3, the upper right dot number 4, and dots below 5 and 6 (Figure 1a) (American Foundation for the Blind, 2019 ; European Commission, 2005; Royal Blind, 2019; PharmaBraille, 2019a).
64 different combinations can be obtained by placing one or more dots in different positions. One cell of a Braille can denote an alphabet letter, a number, a punctuation mark, a mathematical sign, a musical or computer notation, etc. (American Foundation for the Blind, 2019; European Commission, 2005; Royal Blind, 2019; PharmaBraille, 2019a).

A large number of countries that produce Braille, especially great ones, have developed their own standards. These standards define the spaces between the character of the Braille and the minimum height of the dots in each cell of the Braille (Tiresias, 2008). The Marburg Medium Braille standard has been specially created for use on pharmaceutical packaging and labels (Tiresias, 2008; PharmaBraille, 2019b). It is recommended by European and North American standards for pharmaceutical packaging and labels. Below are the specifications (Figure 1b) according to the Marburg Medium Braille standard (PharmaBraille, 2019b):

- The dot diameter is $1.3-1.6 \mathrm{~mm}$.

- The dot spacing is $2.5 \mathrm{~mm}$ from dot centre to dot centre $(a ; b)$.

- The character spacing is $6.0 \mathrm{~mm}$ from dot centre to dot centre (c).

- The cell spacing from dot centre to dot centre with single space between is $12.0 \mathrm{~mm}$ (d).

- The line spacing is $10.0 \mathrm{~mm}$ (e).

The Marburg Medium standard does not define the height of dots in Braille. The CEN standard for pharmaceutical packaging suggests a target dot height of 0.20 $\mathrm{mm}$, for embossing of the material (PharmaBraille, 2019b). A 2008 study (Douglas, Weston \& Whittaker, 2008) concluded that in the range of heights from 0.06 to $0.23 \mathrm{~mm}$, the adequate height of raised Braille dots is $0.18 \mathrm{~mm}$ ( $67 \%$ of participants definitely recognize the text, and $27 \%$ probably), but there is a problem that at this height the surface of the cardboard bursts (Douglas, Weston \& Whittaker, 2008; Golob, Rotar \& Šulc, 2011; Golob et al., 2013). Furthermore, the ECMA Euro Braille standard, in addition to the defined values for spacing between dots, characters and lines, which are identical to the Marburg Medium standard, defines a dot diameter of $1.3 \mathrm{~mm}$ and a target dot height of $0.5 \mathrm{~mm}$ (PharmaBraille, 2019b).

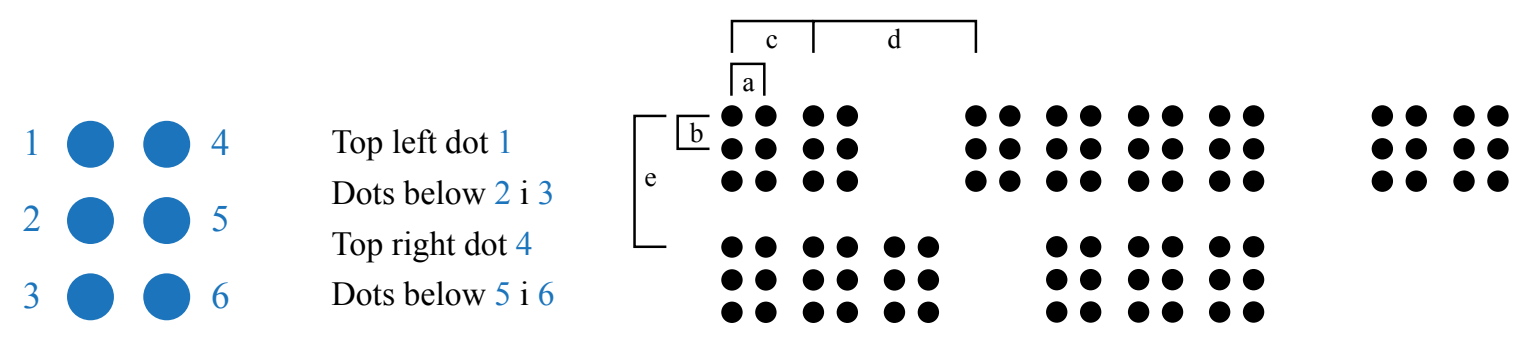

» Figure 1: Position of dots within Braille cell (a) and spacing dimensions (b) (ECMA, 2008) 
Until recently, in order to print Braille, it was necessary to prepare a special embossing matrix for each industrial print. With the progress in the field of screen printing, the possibility of applying varnish and creating dots appeared. For each printing it is necessary to prepare a new screen mesh. With the development of digital printing, great changes and improvements are taking place. The printing form of this technique is in digital format. Since digital printing has replaced screen printing in many fields, and since it also enables application of varnish on the substrate, it is quite logical to ask whether it is possible to print Braille with this technique (Jowat, 2019).

Braille is usually formed on the packaging by embossing. It can be done on a printing machine, a cutting machine, and sometimes on a gluing machine (Figure 2). This procedure is standard for the production of packaging for pharmaceutical products, and in addition it is possible to use labels printed by ink-jet or screen printing technique. The Braille formed on the labels is stronger and more stable compared to the embossed Braille, where the dots may collapse during transport, and also the problem may be to achieve the required dot height (Golob et al., 2013).

a)

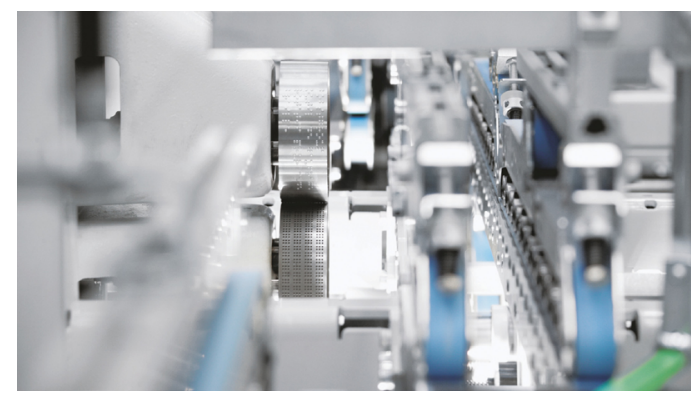

b)

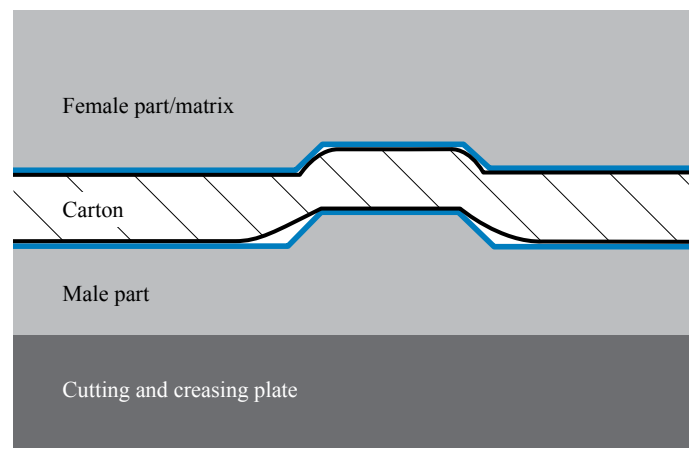

» Figure 2: Braille embossing segment on cardboard packaging gluing machine (a) and diagram of Braille dot embossing process and cardboard deformation (BOBST, 2021; ECMA, 2008)

By analyzing scientific publications and patents Havenko et al. (2013) provided a classification of available methods for Braille dot formation (Yim, 1996; Burman \& Lofstedt, 2001; Labetska, 2012; Kibirkštis, Venyte \& Lydekaitytè, 2012; Labetska \& Havenko, 2012). They can be divided into two groups, namely contact and non-contact methods (Havenko et al., 2013). Contact methods include embossing on cardboard, special types of paper and films and screen printing (Figure 3a) on special papers with thick layers of non-flowing color or mixture, creating relief in the plane due to thermal imprint. And, non-contact methods include ink-jet printing using special composition varnish (Figure $3 b$ ) and methods for obtaining a relief imprint using polymers or other thermochemical materials on electrophotographic printers.

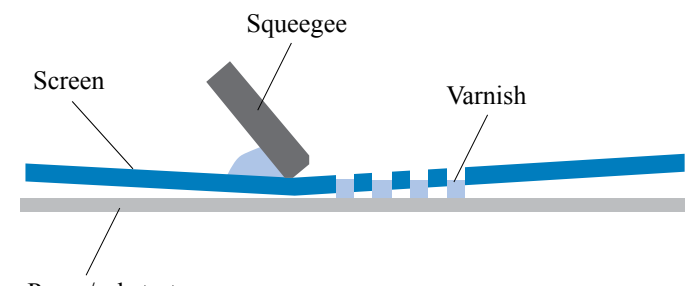

a) Paper/substrate

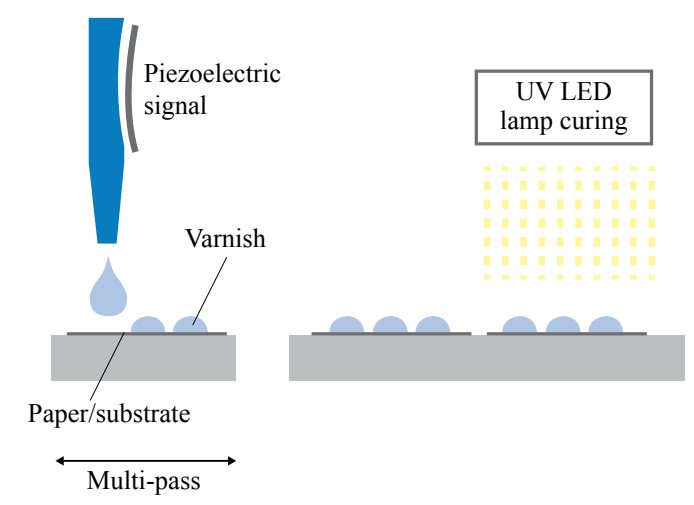

» Figure 3: Screen printing Braille process (a) and UV ink-jet Braille printing (b)

If the existing printing market is analyzed, there are two main methods for creating Braille dots. With the first method, dots are obtained by embossing and it is widely used due to lower costs and faster production. However, this method has significant disadvantages in terms of achieving the appropriate height of Braille dots, as well as their mechanical strength. Since mechanical strength of dots is often not appropriate, it leads to a decrease in the height of the dots during transport or during reading by blind or partially sighted people. Another method of creating Braille dots is the screen printing technique. Its main advantage is the possibility of printing on various materials, such as paper, cardboard, foils, etc. Also, the relief obtained by this printing technique is mechanically more stable and less susceptible to deformation during transport or use by blind and partially sighted persons (Havenko et al., 2013).

When it comes to the reproduction of tactile imprints on self-adhesive labels, there is a problem of creating Braille using the embossing technique. As an alternative, there is the possibility of forming Braille dots using varnish. This can be done by the screen printing technique, but there is a question whether the reproduction by the digital printing technique is possible, as well as 
how many layers of varnish would be needed. Some research has proven the possibility of creating Braille dots using the UV ink-jet printing technique (Golob, Rotar \& Šulc, 2011; Golob et al., 2013; Klisarić, Novaković \& Milić, 2013; Golob et al., 2014; Urbas et al., 2016). In one study, certain technical aspects of the Braille dots reproduction on self-adhesive labels with this printing technique were examined (Havenko et al., 2013). There is still little and insufficient research on the reproduction of Braille dots using the UV ink-jet printing technique on self-adhesive labels. The aim of this paper is to determine whether it is possible to reproduce a Braille dot of appropriate shape and dimensions, with how many layers of varnish and whether blind people can use it.

Digital printing is becoming more and more common, and with this technology it is also possible to form relief, and thus Braille dots on various substrates, including self-adhesive labels. A wide range of materials can be printed using digital ink-jet printing with the use of highly viscous, transparent UV varnish. Important elements in creating Braille dots with ink-jet printing, which affect the size and shape of the Braille dot, are the viscosity of the varnish and the surface stresses of the printing substrate. The quality of digitally printed Braille on various substrates, including self-adhesive labels, depends on numerous factors such as the physical and mechanical characteristics of the substrate and the varnish used, the temperature and pressure of the varnish, the feed rate of the printing substrate, etc. All these factors should be investigated in detail in order to obtain quality tactile imprints using the digital ink-jet printing technique (McCallum \& Ungar, 2003; Creagh \& McDonald, 2003; McCallum et al., 2005; Havenko et al., 2013).

A layer of UV varnish is applied to the substrate by spraying through small nozzles. Liquid varnish is transferred directly to the substrate by spraying, and hardens under the influence of UV light. The drops of varnish are small, usually $6 \mathrm{pL}$, and are fixed by the radiation of the LED light source. Considering the method of application on the substrate, and drying, non-absorbent printing substrates can also be printed (the drying process is instantaneous) (Majnarić, Bolanča Mirković \& Golubović, 2012). Also, therefore, it is possible to apply several layers in the same position. This is important when forming a relief print. If after applying the ink or varnish in one layer, the height is not appropriate, the number of layers can be increased and desired height

a)

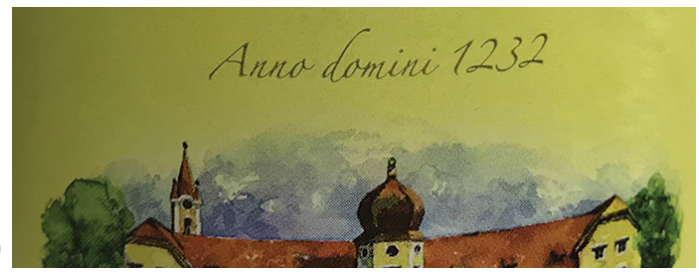

can be achieved (Schär et al., 2015). This allows you to print Braille. It represents a special type of use of structured varnish, and it has expanded to the creative field. For instance, raised elements are used to create illustrations in books for the blind and partially sighted, then for inscriptions in museums and galleries, as well as for descriptive labels (Eccles, 2014; Schär et al., 2015).

By reproducing Braille with ink-jet technology, the problem of deformation and bursting of the material is eliminated, and the information in Braille can be applied to a much wider range of materials. The Braille formed on the labels is stronger and more stable compared to the Braille obtained by embossing, where the dots may collapse during transport, and also the problem may be to achieve the required dot height (Golob et al., 2013). Considering the transparency of UV varnish, the text in Braille created with this technique does not affect people who have normal vision, when detecting printed information.

\section{Materials and methods}

This paper examines the legibility of tactile imprints formed by UV varnish on printing machine VersaUV LEC 300 (Roland DG Corporation, Japan, 2011) on ScandCoat MC self-adhesive label paper. Unlike other research, Braille was applied to previously printed material (label). The label was printed using the flexographic printing technique on the Nilpeter FA-4 machine (Nilpeter A/S, Denmark 2015). An actual design was printed. The ink printing order was CMYK. The part of the label on which the Braille was applied was previously printed with $40 \%$ yellow colour. UV curing Flint Flexocure UFR 10082 ink was used for printing. The aim was to determine whether it is possible to reproduce a quality and legible Braille using the UV printing technique on self-adhesive paper, in order to be able to label products for blind and partially sighted people. Also, the goal was to determine how many layers of varnish are optimal for obtaining a satisfactory quality in terms of height and size of Braille dots, and their legibility. Below is more information about the used paper, the method for reproduction of the prints, as well as the method for their evaluation.

The inscription in Braille was as follows: graševina bijelo vino berba 2013. Figure 4 shows an enlarged photograph of part of the label before and after the printing of the Braille text.

b)

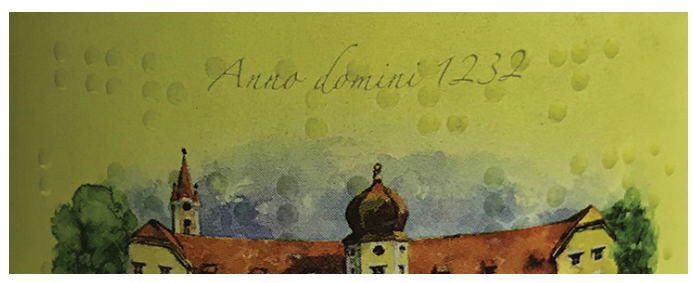

» Figure 4: Printed self-adhesive label (a) and label with printed Braille text using 12 layers of varnish (b) 


\section{Printing substrate}

ScandCoat MC is a machine coated paper, with medium gloss and good whiteness. It is a versatile paper, suitable for a very wide range of primary label work. It is suitable for colour printing, with different printing techniques: flexography, rotary or flat-bed letterpress, offset lithography, screen printing process and can be foil blocked and varnished. It is important to note that it is suitable for use in food packaging, with limited contact with food, as well as in packaging for products intended for children.

Material characterization was performed according to the following parameters: calliper (ISO 534), basis weight (ISO 536), roughness (ISO 8791-4), brightness (ISO 2470) and opacity (ISO 2471). The characteristics of the used self-adhesive label paper are given in Table 1. The data are taken from the paper manufacturer datasheet.

\section{UV varnish and Braille printing process on samples}

In order to form Braille dots, liquid UV varnish was transferred directly to the printing substrate, in this case a printed label, and then cured with UV light. ECO-UV varnish, EUV-GL v.4, the following compositions were used (Roland, 2019): 1,6-Hexamethylene diacrylate 20-30\%, 2-Methoxyethyl acrylate 20-24\%, Benzyl acrylate 10-25\%, N-Vinyl caprolactam 10-20\% and Diphenyl (2,4,6-trimethylbenzoyl) phosphine oxide 5-10\%. The printing was done in 8, 10, 12, 14 and 16 layers, in order to achieve the appropriate height of the relief. Gloss mode (drying with one UV lamp) was used for printing. The print resolution was $740 \times 1440$ $\mathrm{dpi}$. The direction of printing was set to unidirection, and rasterization was done according to the dither method. Printing was done in high quality mode- higher amount of varnish and resolution, and lower speed. It is printed using a DX4 Epson piezo Inkjet head with dot size of 3.5 pL (Format Media Ltd., 2010). After 5 layers, the height of the head was changed to a higher level.

\section{Instrumental measurements}

An electro-mechanical surface roughness tester- perthometer S8P (MAHR PERTHEM, Germany 1988) was used (Figure 5). The test was performed in accordance with ISO standard $3274 / 75$. The device was used to determine the profile of the Braille dot reproduced with different number of layers, as well as its diameter.
The height of the Braille dots was measured using an electronic micrometer, with a division of $0.01 \mathrm{~mm}$. The micrometer used has a larger contact head, and it covered three dots at the same time. The height of the Braille dots was measured 10 times at different positions. Height was measured along with paper thickness. Then, by subtracting the thickness of the paper, the height of the formed Braille dots was obtained and an average of 10 measurements was taken.

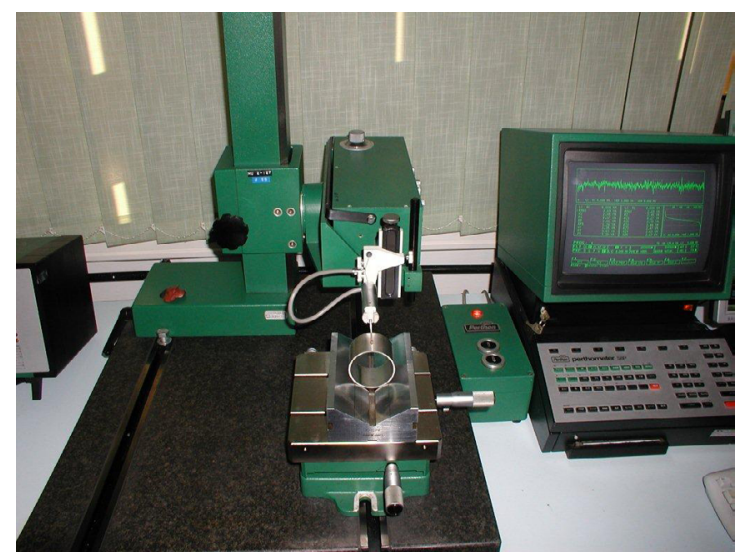

» Figure 5: Perthometer S8P

\section{Blind and partially sighted people survey}

The survey was conducted among blind and partially sighted people in the Association of the Blind of the Zagreb City and at the High School for the Blind and Visually Impaired "Vinko Bek". The survey involved 24 respondents, of different ages and genders, different levels of education, as well as different experience in knowing and using Braille.

Twelve men and twelve women took part in the survey. 5 respondents are under 20 years of age, 3 respondents are aged 21-30 years, 1 respondent is 31-40 years old, 4 respondents are 41-50 years old, 8 respondents are 51-60 years old, and 3 respondents are over 60 years old. 17 of them have a secondary education, while 7 of them have a university degree. 9 respondents have used Braille for less than 20 years, 10 of them between 21-40 years, while 5 of them have known Braille for more than 40 years.

The samples were evaluated according to the quality of the Braille dots (cells), i.e. the height of the Braille dots

\section{Table 1}

Characteristics of used self-adhesive label paper

\begin{tabular}{l|c|c|c|c|c}
\hline Paper type & $\begin{array}{c}\text { Thickness } \mu \mathrm{m} \\
\text { (ISO 534) }\end{array}$ & $\begin{array}{c}\text { Basis weight } \mathbf{g} / \mathbf{m}^{2} \\
\text { (ISO 536) }\end{array}$ & $\begin{array}{c}\text { Roughness } \mu \mathrm{m} \\
\text { (ISO 8791-4) }\end{array}$ & $\begin{array}{c}\text { Brightness \% } \\
\text { (ISO 2470) }\end{array}$ & $\begin{array}{c}\text { Opacity \% } \\
\text { (ISO 2471) }\end{array}$ \\
\hline ScandCoat MC & $65 \pm 5$ & $80 \pm 3$ & 1 & 93 & 89 \\
\hline
\end{tabular}


and their tangibility, and the legibility of the Braille text. Both criteria were evaluated with grades from 1 to 5 , where the scale looked like this: 1- insufficient legibility, 2- sufficient legibility, 3-good legibility, 4- very good legibility, 5-excellent legibility, i.e. to assess the quality of the sample: 1 - insufficient quality, 2 - sufficient quality, 3 good quality, 4- very good quality and 5- excellent quality.

\section{Results and discussion}

\section{Results of instrumental measurements}

Figure 6 presents the obtained results of the diameter of reproduced dots for five samples, in which the number of varnish layers was successively increased. As can be seen from the figure, the diameter of Braille dots in all samples is below the standard value. When reproducing Braille dots using 8 layers of varnish, the diameter of the dot is the smallest. As the number of layers increases, the diameter of the dot also increases. It can be noticed that the change of the diameter is greatest between prints reproduced with 8 and 10 layers, while with further increasing the number of layers of varnish, the diameter of the dot slightly increases. Thus, it can be concluded that first application of UV varnish leads to the partial penetration of the varnish into the paper and the spreading of the Braille dot around its base. After, the surface of the paper is covered with polymerized UV varnish, and the next layers of varnish are applied to the given surface. Spreading of the varnish is reduced, and depends on amount of varnish that flows over the edges of previously polymerized layer. After applying 10 layers of UV varnish, spreading is reduced to minimum, since amount of applied varnish slightly flows over the edges of polymerized layers.

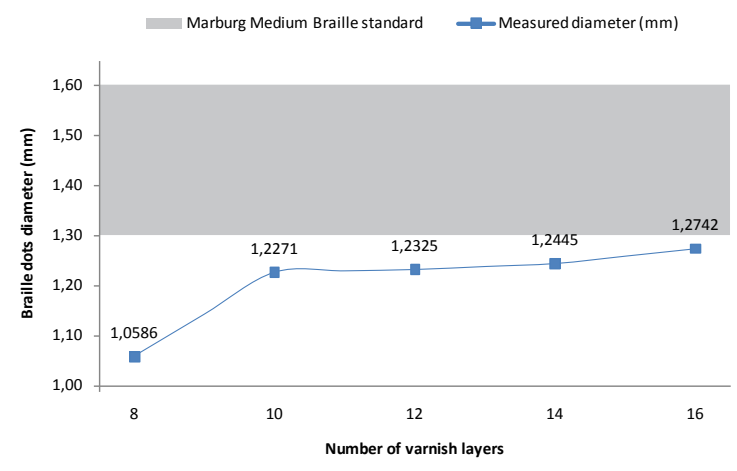

»Figure 6: Diameter of Braille dots reproduced with different number of layers of varnish

Figure 7 presents the profiles of Braille dots formed by a different number of layers of varnish, obtained using a S8P perthometer. From the presented profiles it can be noticed that the shape of the formed dots is domed and that the peak of the dot is approximately in its centre. The dot is slightly rounded at the top. There is impression of a dot that is comfortable under the fingers, but raised enough, that it can be tactilely felt and recognized.

a)

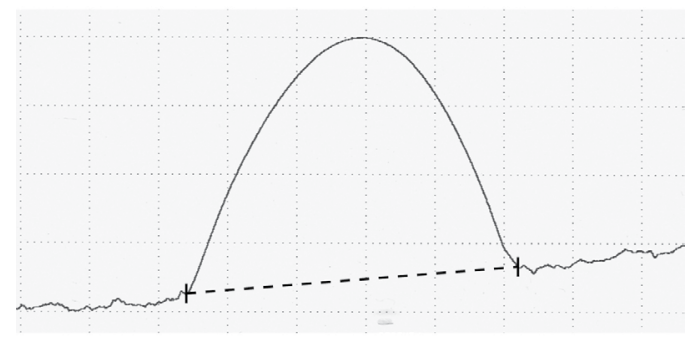

b)
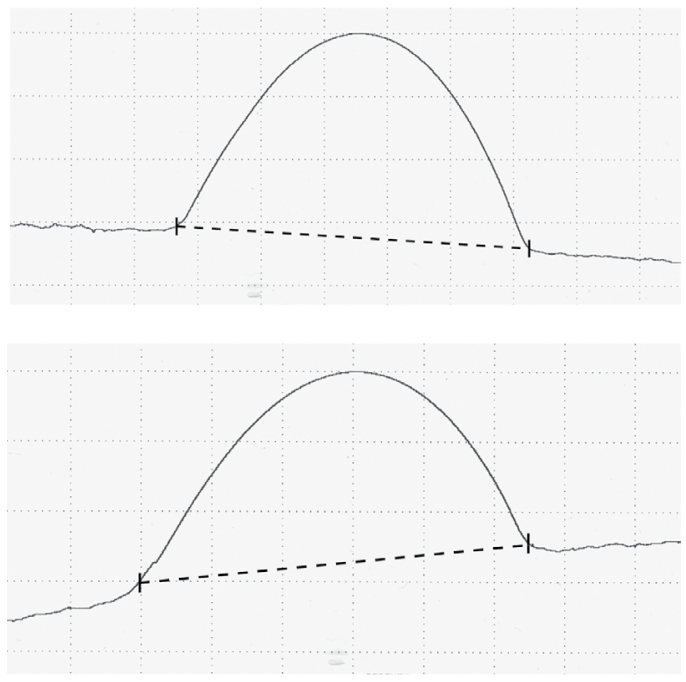

d)

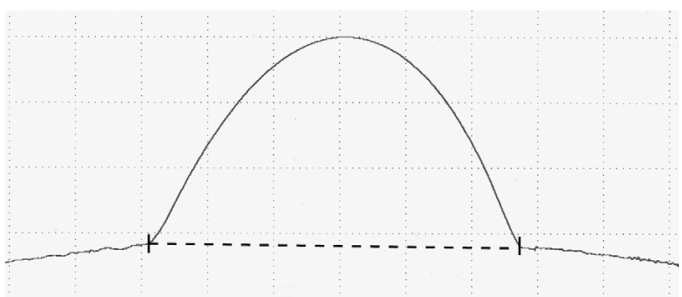

e)

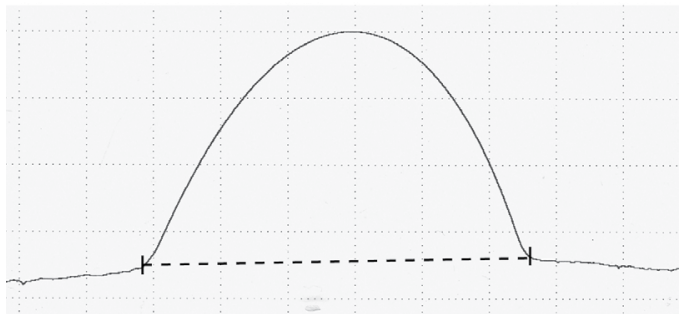

» Figure 7: Braille dot profile printed with $8(a), 10$ (b), 12 (c), 14 (d) and 16 layers of varnish (e) measured with perthometer S8P

Figure 8 presents the obtained results of the dots height. Two parts of the curve trend can be seen from the figure. In the first part, from 8 to 12 layers of varnish, the increase is almost linear. The difference between 8 and 10 layers of varnish, as well as 10 and 12 is approximately the same. In the first case it is 0.06 
$\mathrm{mm}$, while in the second it is $0.05 \mathrm{~mm}$. Further, an exponential increase in the height of the dot is observed. The difference in height increases successively, thus the difference between 12 and 14 layers of varnish is $0.14 \mathrm{~mm}$, and between 14 and 16 coats $0.19 \mathrm{~mm}$.

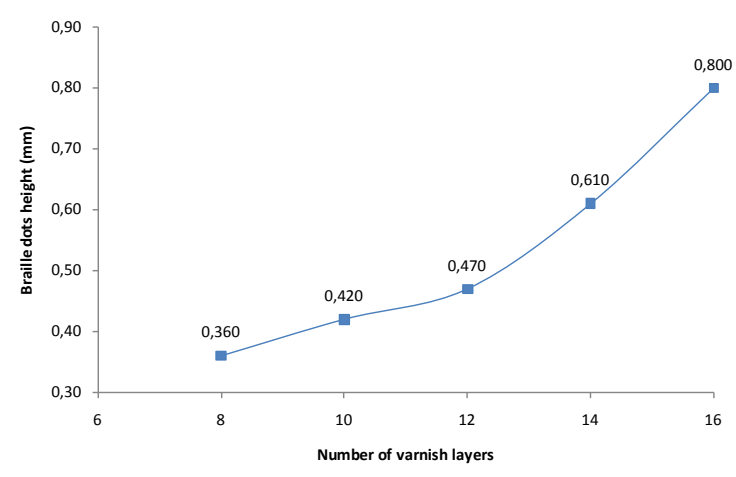

» Figure 8: Height of Braille dots reproduced with different number of layers of varnish

Based on the above, it can be concluded that at first there is a slightly larger increase in the diameter of the dot, i.e. spreading of the varnish during application, and a smaller increase in the height of the dot. With further application of layers of varnish, the diameter of the dot remains approximately the same, but the height of the dot shows a larger increase. Therefore, there is less spreading of varnish around the dot base, and thus the height of the dot increases. This can be explained by contact angle. According to Urbas et al. (2016), contact angle was smaller in case of unprinted surface than the surface covered with polymerized UV varnish. It can also be observed that the height of the dot in the sample with 12 layers of varnish is approximately equal to the target height of $0.5 \mathrm{~mm}$, suggested by the ECMA Euro Braille standard.

\section{Results of blind and partially sighted people survey}

Table 2 presents the average values of assessments of the quality of Braille dots, and their legibility, by 24 respondents. When assessing the quality of the reproduction, the respondents were asked to arrange the reproduced samples with Braille from the worst to the best, depending on the quality of the Braille dots, i.e. the height of the Braille dots and their tangibility. In the legibility assessment, the subjects received the samples in random order, without knowing that the samples were formed by a different number of layers of varnish, and had to give a legibility rating for each sample in the range of 1-5, where grade 1 was insufficient legibility, and grade 5 excellent legibility. It can be seen from the table that the grades for both quality and legibility increase with increasing the number of varnish layers.

The average grade for quality of Braille dots reproduced with 8 layers of varnish is 1.04 , and for the legibility is 2.71 , while the highest average grade has a sample reproduced with 16 layers of varnish, 4.67 for quality and 4.88 for legibility. Based on the given assessments, it can be concluded that the quality of reproduction and legibility of Braille dots obtained with 8 and 10 layers of varnish are not very satisfactory, and that the samples reproduced in this way do not meet the requirements. The sample obtained with 12 layers has a very high legibility grade (4.00), while the mutual evaluation of print production quality is quite solid (3.17), and it can be concluded that with 12 layers of varnish satisfactory prints are produced, in terms of reproduction quality and legibility. By further increasing number of the layers the average grade increases and, by looking at these values it can be concluded that the highest quality samples are produced with 16 layers of varnish. Here it is important to establish a compromise, and choose samples that have satisfactory grades for both criteria, and require less time and less material consumption. Hence, find the right ratio of quality and economy. According to the given grades, it can be seen that the threshold for good prints would be the application of 12 layers of varnish, and the prints reproduced that way would be considered appropriate, and compared to prints with 14 and 16 layers of varnish, which received higher grades for two given parameters, they require less production time as well as less varnish consumption.

Below is a statistical overview of the results of the mutual evaluation of the reproduction quality of prints (Figure 9), and the legibility of the formed Braille dots (Figure 10), based on blind people survey. Figures show minimum and maximum grades given to each individual sample, the average value, and the value of standard deviation.

Also, there is a correlation graph (Figure 11) representing legibility and dot height reproduction quality, based on number of varnish layers, showing correlation between influencing factors. On the graph there are

Table 2

Average values of grades of legibility and quality of reproduced samples

\begin{tabular}{l|c|c|c|c|c}
\hline Number of layers of varnish & $\mathbf{8}$ layers & 10 layers & 12 layers & 14 layers & 16 layers \\
\hline $\begin{array}{l}\text { Average grade of Braille dot } \\
\text { height reproduction quality }\end{array}$ & 1.04 & 2.00 & 3.17 & 4.13 & 4.67 \\
\hline $\begin{array}{l}\text { Average grade of } \\
\text { Braille legibility }\end{array}$ & 2.71 & 3.58 & 4.00 & 4.54 & 4.88 \\
\hline
\end{tabular}


also R-squared values, which are for both variables near 1 . Thus, it can be concluded that there is a high positive correlation between legibility and dot height reproduction quality and number of varnish layers.

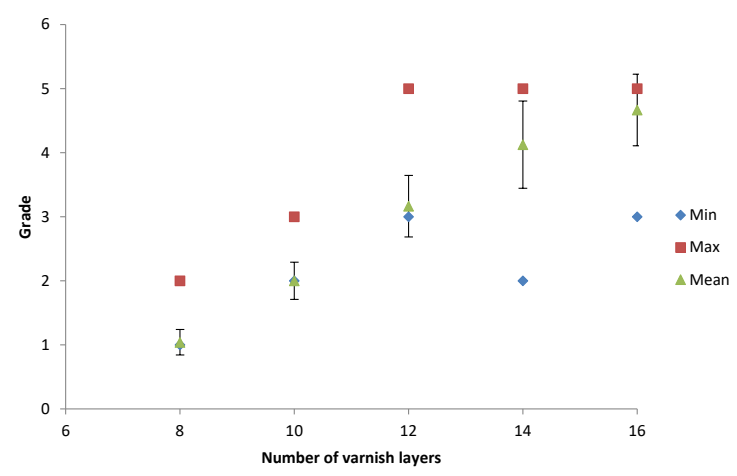

» Figure 9: Evaluation of the reproduction quality of the Braille dots height with a different number of layers of varnish

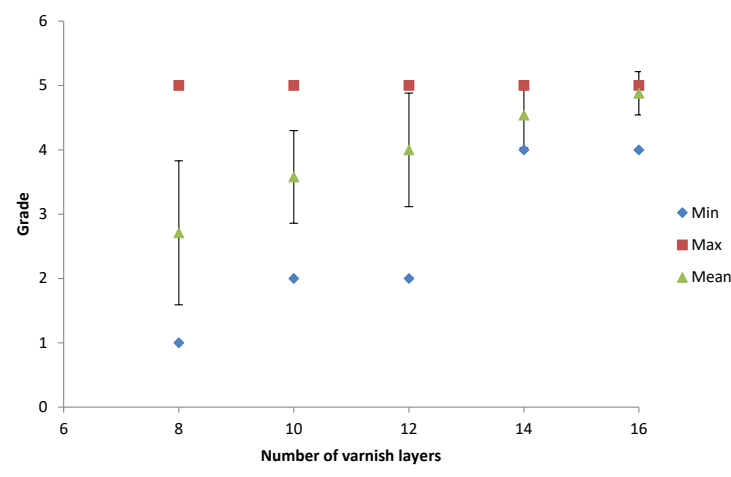

» Figure 10: Evaluation of the legibility of Braille reproduced with a different number of layers of varnish

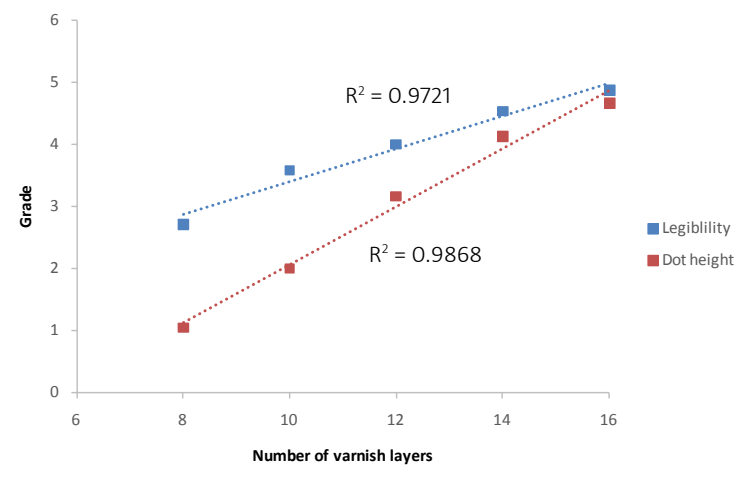

„ Figure 11: Correlation graph representing legibility and dot height based on number of varnish layers

\section{Conclusion}

Labelling of products in Braille is currently mandatory for products of the pharmaceutical industry, but it can be expected that in the near future it will be mandatory for products of other branches of industry, primarily food and chemical. Therefore, the possibility of reproducing Braille using UV varnish and UV ink-jet printing technique on self-adhesive label paper was investigated. The paper was previously printed using the flexo printing technique with Flint UV ink. An actual design was printed. The ink printing order was CMYK. Braille was then printed on the surface of the paper that was printed with $40 \%$ yellow. It was printed with 8, 10, 12, 14 and 16 layers, on a UV ink-jet machine Roland VersaUV LEC300. Instrumental measurements of the height and the diameter of the dot, as key parameters, were performed. Also, a survey was conducted among blind and partially sighted people, in order to examine the legibility and quality of the production of printed samples, since the labelling in Braille is intended for this group of people.

In the case of a Braille reproduced with varnish, the height does not have to be a decisive factor in easier reading as in the case of a Braille made by embossing. Varnish hardness and accurate shape of the dot are also important. It has been determined by instrumental means that with the increase in the number of varnish layers, there is an increase in both the height and the diameter of the reproduced dot. First, there is a larger increase in diameter, and a smaller increase in the height of the dot. It can be assumed that it is caused by spreading of the varnish around the dot base. After that, with further application of varnish layers, there is a larger increase in the height of the dot, while the increase in diameter is insignificant. This can be explained by the fact that with 10 layers of UV varnish applied, spreading is reduced to minimum, since amount of varnish in one layer slightly flows over the edges of polymerized layers. The diameter of the reproduced dot for all samples is smaller than it is defined in Marburg Medium standard. But, with 10 layers of varnish $(1.2271 \mathrm{~mm})$ diameter slightly approaches the lower limit prescribed by this standard, i.e. the diameter prescribed by the ECMA Euro Braille standard (1.3 mm). With 16 layers of varnish this value is almost reached (1.2742 $\mathrm{mm})$. The optimal dot height, which is defined by the ECMA Euro Braille $(0.5 \mathrm{~mm})$ and many other standards (British, American, German, Italian, Japanese, Swedish, etc.), was approximately obtained with 12 layers of varnish $(0.47 \mathrm{~mm})$. With a further increasing number of layers of varnish there is a significant increase in the height of the dot and it exceeds the standard value. For 14 layers of varnish it is $0.61 \mathrm{~mm}$. Longer reading of the text in Braille, which has a higher dot, can lead to fatigue, as well as the possibility of damage to the fingertips.

Also, the analysis of the profile of Braille dots, obtained with a perthometer, founded that the created dot has a domed shape and that its peak is approximately in the centre of the dot. This is very important for detection of the dot and finger comfort. 
Based on the conducted survey and the presented and analyzed results, it can be concluded that it is possible to reproduce tactile prints of appropriate quality and legibility using UV varnish and UV ink-jet printing on the presented self-adhesive label paper. Samples reproduced with 8 and 10 layers of varnish received bad grades for legibility, and especially for the quality of print reproduction, and were ranked as the worst reproduced. Samples in which the Braille dot was formed using 12 layers of varnish received very good grades for legibility and good grades for quality, and it can be concluded that they represent samples of appropriate quality and legibility. Samples reproduced with an even greater number of layers of varnish, 14 and 16, received even better grades in terms of legibility and quality of reproduction.

From all the above, it can be concluded that it is possible to reproduce quality Braille using UV ink-jet printing, and that for a quality reproduction a minimum of 12 layers of varnish is needed. Thinking about rationalizing costs and time, it is recommended to use 12 layers of varnish, because they represent the threshold for a quality Braille dot on the presented paper. Further increase of the varnish application leads to better reproduction and more readable print, according to the respondents, but there is also an increase in the consumption of the UV varnish, as well as the time required for the reproduction of samples. In addition, the height of the dot exceeds the height prescribed by the ECMA Euro Braille, as well as many others standards. This can be a problem with longer reading. It can be unusual for users accustomed to a lower Braille dot and, it can also reduce sensitivity in the fingertips.

Since the printing substrate itself directly affects the height of the applied varnish, future research should be focused on this. The quality of Braille dots and the legibility of Braille formed on different types of label papers, as well as some other types of substrates: plexiglass, glass, wood, etc., should be examined. Also, further research should be focused on examining the durability of the Braille dot formed by the technique of UV ink-jet printing on abrasion and tearing, the influence of light and temperature, etc.

\section{References}

Ackland, P., Resnikoff, S. \& Bourne, R. (2017) World blindness and visual impairment: despite many successes, the problem is growing. Community eye health. 30 (100), 71-73.

American Foundation for the Blind (2019) What Is Braille?. Available from: https://www.afb. org/blindness-and-low-vision/braille/whatbraille [Accessed: 13th December 2019].

BOBST (2021) ACCUBRAILLE - Braille embossing. Available from: https://www.bobst.com/ncen/products/ folding-gluing/complementary-products/overview/ machine/accubraille-gt/ [Accessed: 30th May 2021]. Bourne, R.R.A., Flaxman, S.R., Braithwaite, T., Cicinelli, M.V., Das, A., Jonas, J.B., Keeffe, J., Kempen, J.H., Leasher, J., Limburg, H., Naidoo, K., Pesudovs, K., Resnikoff, S., Silvester, A., Stevens, G.A., Tahhan, N., Wong, T.Y., Taylor, H.R.; Vision Loss Expert Group (2017) Magnitude, temporal trends, and projections of the global prevalence of blindness and distance and near vision impairment: a systematic review and meta-analysis. The Lancet Global Health. 5 (9), e888-e897. Available from: doi: 10.1016/S2214-109X(17)30293-0.

Burman, P. \& Lofstedt, B. (2001) Printer head for a Braille printer and a method of manufacturing the same. United States Patent 6241405 B1 (Patent).

Creagh, L.T. \& McDonald, M. (2003) Design and performance of ink-jet printheads for non-graphics-arts applications. MRS Bulletin. 28 (11), 807-811. Available from: doi: 10.1557/mrs2003.229.

Douglas, G., Weston, A. \& Whittaker, J. (2008) Braille dot height research: Investigation of Braille Dot Elevation on Pharmaceutical Products. University of Birmingham. Final report 2008. Available from: https://www.birmingham.ac.uk/Documents/ college-social-sciences/education/victar/brailledot-height.pdf [Accessed: 28th June 2021].

EBU (2019) About blindness and partial sight - facts and figures. Available from: http://www.euroblind. org/about-blindness-and-partial-sight/factsand-figures [Accessed: 5th December 2019].

Eccles, S. (2014) How to print 3D with a UV digital inkjet. Available from: http://www.fespa.com/ news/features/how-to-print-3d-with-a-uv-digital-inkjet.html [Accessed: 13th February 2015].

ECMA (2008) Braille on Folding Cartons.

The Hague, ECMA.

European Commission (2005) Guidance concerning the Braille requirements for labelling and the package leaflet. Brussels, European Commission. Available from: https://www.gmp-compliance.org/files/guidemgr/ Braille_text20050411.pdf [Accessed: 28th June 2021].

Format Media Ltd. (2010) DX4 Printhead - 1000002201 - for Epson, Roland, Mimaki and Mutoh. Available from: https://www.largeformatreview. com/hardware/wide-format-print/dx4-printhead-1000002201-for-roland-mimaki-and-mutoh-1000002201 [Accessed: 23rd June 2021]

Fricke, T., Tahhan, N., Resnikoff, S., Papas, E., Burnett, A., Ho, S., Naduvilath, T. \& Naidoo, K. (2018) Global Prevalence of Presbyopia and Vision Impairment from Uncorrected Presbyopia. Ophthalmology. 125 (10), 1492 - 1499. Available from: doi: 10.1016/j.ophtha.2018.04.013.

Golob, G., Gregor-Svetec, D., Leskovšek, A., Turnšek, A., Majnarić, I., Dudok, T., Mayik, V. \& Urbas, R. (2014) Braille text and raised images used in books for children who are blind or visually impaired. 
In: Urbas, R. (ed.) Proceedings 7th International Symposium of Information and Graphic Arts Technology, 5-6 June 2014, Ljubljana, Slovenia. Ljubljana, Faculty of Natural Sciences and Engineering, Department of Textiles, Chair of Information and Graphic Art Technology. pp. 109-111.

Golob, G., Gregor Svetec, D., Urbas, R., Rotar, B., Jereb, N., Mayik, V. \& Dudok, T. (2013) Dot shape and legibility analysis of multilayer UV ink-jet printed Braille text. In: XIth Symposium on Graphic Arts, 17-18 June 2013, Pardubice, Czech Republic. Pardubice, Department of Graphic Arts and Photophysics. pp. 61-65.

Golob, G., Rotar, B. \& Šulc, D. (2011) Braille dot height impact on the functionality and legibility of the pharmaceutical packaging. In: Enlund, N. and Lovreček, M. (eds.) Advances in Printing and Media Technology, Proceedings of the 38th International Research Conference of iarigai, 11-14 September 2011, Budapest-Debrecen, Hungary. Darmstadt, The International Association of Research Organizations for the Information, Media and Graphic Arts Industries. pp. 293-299.

Hashemi, H., Yekta, A., Jafarzadehpur, E., Doostdar, A., Ostadimoghaddam, H., \& Khabazkhoob, M. (2017) The prevalence of visual impairment and blindness in underserved rural areas: a crucial issue for future. Eye (London, England). 31 (8), 1221-1228. Available from: doi: 10.1038/eye.2017.68.

Havenko, S., Labetska, M., Stępień, K., Kibirkštis, E. \& Venytè, I. (2013) Research of influencing factors on the change of geometric parameters of Braille elements on self-adhesive labels. Mechanika. 19 (6), 716721. Available from: doi: 10.5755/j01.mech.19.6.6016.

Jowat (2019) Structural Braille Varnish. Available from: https://www.jowat.com/fileadmin/dokumente/anwendungen/PDFs_Al_PV/AI_Braille_ EN.pdf [Accessed: 5th December 2019].

Kibirkštis, E., Venytè, I. \& Lydekaitytè, J. (2012) Resistance to mechanical effect of Braille dot surface, formed on different materials. In: VII International Scientific-Practical Conference Book quality, 6-8 June 2012, Lviv, Ukraine. Lviv, Ukrainian Academy of Printing. pp. 144-150.

Klisarić, V., Novaković, D. \& Milić, N. (2013) Ispitivanje taktilnih otisaka sa brajevim pismom reprodukovanih UV ink-jet tehnologijom štampe. Zbornik radova Fakulteta tehničkih nauka. 28 (7), 1302-1305.

Labetska, M.T. (2012) Analytical research of technological features of thermographic printing. Book quality. 1 (21), 123-128.

Labetska, M.T. \& Havenko, S.F. (2012) Research of performance indicators of Braille relief-dot elements on packaging. In: I International Scientific-Practical Conference Packaging industry: modern tendencies of development and specialists training, 2012, Lviv, Ukraine. Lviv, Ukrainian Academy of Printing. pp. 111-114.
Majnarić, I., Bolanča Mirković, I. \& Golubović, K. (2012) Influence of UV curing varnish coating on surface properties of paper. Tehnički Vjesnik. 19 (1), 51-56.

McCallum, D. \& Ungar, S. (2003) An introduction to the use of inkjet for tactile diagram production. The British Journal of Visual Impairment. 21 (2), 73-77. Available from: doi: 10.1177/026461960302100206

McCallum, D., Ahmed, K., Jehoel, S., Dinar, S. \& Sheldon, D. (2005) The design and manufacture of tactile maps using an inkjet process. Journal of Engineering Design. 16 (6), 525-544. Available from: doi: 10.1080/09544820500273946.

Pascolini, D. \& Mariotti, S.P. (2011) Global Estimates of Visual Impairment: 2010. The British journal of ophthalmology. 96 (5), 614-618. Available from: doi: 10.1136/bjophthalmol-2011-300539.

PharmaBraille (2019a) The Braille Alphabet. Available from: https://www. pharmabraille.com/ pharmaceutical-braille/the-braille-alphabet/ [Accessed: 13th December 2019].

PharmaBraille (2019b) Marburg Medium Braille Font Standard. Available from: https://www. pharmabraille.com/pharmaceutical-braille/marburg-medium-font-standard/ [Accessed: 25th December 2019].

Roland (2019) ECO-UV, EUV-GL Ver. 2 - Safety Data Sheet. Roland DG Corporation. Available from: https://www.rolanddg.kr/-/media/roland-apac/ dgk/files/support/sds/euv2/euv2_gl_20190524. pdf?la=ko\&hash=B32C66BE4710D421B5A77C848C488A74CF22A566 [Accessed: 28th June 2021].

Royal Blind (2019) Braille Facts. Available from: https:// www.royalblind.org/national-braille-week/aboutbraille/braille-facts [Accessed: 13th December 2019].

Schär, M., Krivec, T., Golob, G. \& Selbmann, K.-H. (2015) Yellowing of thick-film coatings printed with UV-curable inkjet varnishes. Advances in printing and media technology. 42, 265-274.

Tiresias (2008) Braille Cell Dimensions. Available from: http://www.arch.mcgill.ca/prof/klopp/ arch678/fall2008/3\%20Student\%20 exchange/ Team\%20Surface/Connexion\%20Surface\%20 Folder/MA\%20files/Braille\%20cell\%20dimensions.pdf [Accessed: 25th December 2019].

Urbas, R., Rotar, B., Hajdú, P. \& Elesini, U.S. (2016) Evaluation of the modified braille dots printed with the UV ink-jet technique. Journal of Graphic Engineering and Design. 7 (2), 15-24. Available from: doi: 10.24867/JGED-2016-2-015.

VisionAware (2019) All About Braille. Available from: https://www.visionaware.org/info/everyday-living/ essential-skills/reading-writing-and-vision-loss/allabout-braille/1235 [Accessed: 7th December 2019].

WHO (2019) World report on vision. World Health Organization. Available from: https://www. who.int/publications/i/item/9789241516570 [Accessed: 28th June 2021]. 
Yim, J. M. (1996) Touch-readable product and associated process. World Intellectual Property

Organization WO1996041320A1 (Patent).

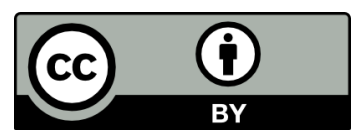

(C) 2021 Authors. Published by the University of Novi Sad, Faculty of Technical Sciences, Department of Graphic Engineering and Design. This article is an open access article distributed under the terms and conditions of the Creative Commons Attribution license 3.0 Serbia (http://creativecommons.org/licenses/by/3.0/rs/). 